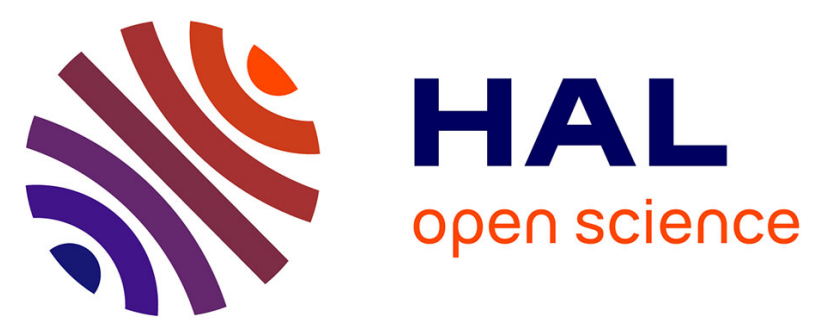

\title{
Are There Any Left-Right Asymmetries in Saccade Parameters? Examination of Latency, Gain, and Peak Velocity
}

Dorine Vergilino-Perez, Alexandra Fayel, Christelle Lemoine, Patrice Senot, Judith Vergne, Karine Doré-Mazars

\section{To cite this version:}

Dorine Vergilino-Perez, Alexandra Fayel, Christelle Lemoine, Patrice Senot, Judith Vergne, et al.. Are There Any Left-Right Asymmetries in Saccade Parameters? Examination of Latency, Gain, and Peak Velocity. Investigative Ophthalmology \& Visual Science, 2012, 53 (7), pp.3340. 10.1167/iovs.11-9273 . hal-03137731

\section{HAL Id: hal-03137731 https://hal.science/hal-03137731}

Submitted on 10 Feb 2021

HAL is a multi-disciplinary open access archive for the deposit and dissemination of scientific research documents, whether they are published or not. The documents may come from teaching and research institutions in France or abroad, or from public or private research centers.
L'archive ouverte pluridisciplinaire HAL, est destinée au dépôt et à la diffusion de documents scientifiques de niveau recherche, publiés ou non, émanant des établissements d'enseignement et de recherche français ou étrangers, des laboratoires publics ou privés. 


\title{
Are There Any Left-Right Asymmetries in Saccade Parameters? Examination of Latency, Gain, and Peak Velocity
}

\author{
Dorine Vergilino-Perez, ${ }^{1,2}$ Alexandra Fayel, ${ }^{1}$ Christelle Lemoine, ${ }^{1}$ Patrice Senot, ${ }^{1}$ Judith Vergne, ${ }^{1}$ \\ and Karine Doré-Mazars ${ }^{1,2}$
}

Purpose. Hemispheric specialization in saccadic control is still under debate. Here we examine the latency, gain, and peak velocity of reactive and voluntary leftward and rightward saccades to assess the respective roles of eye and hand dominance.

Methods. Participants with contrasting hand and eye dominance were asked to make saccades toward a target displayed at $5^{\circ}, 10^{\circ}$, or $15^{\circ}$ left or right of the central fixation point. In separate sessions, reactive and voluntary saccades were elicited by Gap-200, Gap-0, Overlap-600, and Antisaccade procedures.

REsults. Left-right asymmetries were not found in saccade latencies but appeared in saccade gain and peak velocity. Regardless of the dominant hand, saccades directed to the ipsilateral side relative to the dominant eye had larger amplitudes and faster peak velocities.

Conclusions. Left-right asymmetries can be explained by nasotemporal differences for some subjects and by eye dominance for others. Further investigations are needed to examine saccadic parameters more systematically in relation to eye dominance. Indeed, any method that allows one to determine ocular dominance from objective measures based on saccade parameters should greatly benefit clinical applications, such as monovision surgery. (Invest Opbthalmol Vis Sci. 2012; 53:3340-3348) DOI:10.1167/iovs.11-9273

$\mathrm{O}$ ne of the fundamental characteristics of the human brain is hemispheric asymmetry. Consequently, the question of cerebral dominance for perceptual, motor, and cognitive processes has been central to much research in cognitive psychology or neurosciences. ${ }^{1,2}$ The left hemisphere's specialization for language and the right hemisphere's specialization for spatial processing are two long-standing examples of perceptual asymmetries. In the motor domain, handedness is probably the best-known asymmetry and explains why the

From the ${ }^{1}$ Laboratoire Vision Action Cognition Institut Universitaire Paris Descartes de Psychologie (IUPDP), Université Paris Descartes, Sorbonne Paris Cité, Institut de Psychologie, Boulogne Billancourt, France; and ${ }^{2}$ Institut Universitaire de France, Paris, France.

Submitted for publication December 8, 2011; revised March 30, 2012; accepted April 13, 2012.

Disclosure: D. Vergilino-Perez, None; A. Fayel, None; C. Lemoine, None; P. Senot, None; J. Vergne, None; K. DoréMazars, None

Corresponding author: Dorine Vergilino-Perez, Laboratoire Vision Action Cognition, IUPDP Université Paris Descartes, 71 Avenue Edouard Vaillant, 92774 Boulogne Billancourt Cedex, Paris, France; dorine.vergilino-perez@parisdescartes.fr. hemispheric specialization in motor control has been studied mainly from hand movements ${ }^{2}$ rather than from eye movements, even though eye movements provide the most powerful interface between perception and action. Indeed, saccades, which rapidly and accurately guide the gaze from one point of interest in the visual field to another, allow us to act in our visual environment.

Saccades are described by their latency (time before their execution), their metrics (direction and amplitude), and their dynamic (velocity, acceleration, and so forth). Some earlier studies of saccade characteristics have reported that rightward saccades have shorter latencies than leftward saccades. ${ }^{3,4}$ This left-right asymmetry, which was found for right-handers and not for left-handers, was taken as a behavioral indicator of hemispheric specialization for oculomotor control, with the left hemisphere being more efficient than the right at executing visuomotor tasks.

The issue of hemispheric specialization in saccadic control remains under debate, however, as the asymmetry observed in saccade latency has not always been demonstrated. One study ${ }^{5}$ failed to replicate it in data averaged over subjects but found it at the individual level in tasks involving reactive or voluntary saccades: 6 of 12 subjects systematically made rightward saccades after a shorter latency than leftward saccades, whereas two other subjects presented the reverse pattern. As the asymmetry was found not only for reactive saccades but also for voluntary ones guided by a central cue, a perceptual or neural explanation was rejected in favor of a more cognitive one linked to a visuospatial attention bias specific to individuals. Another study ${ }^{6}$ showed individual differences between leftward and rightward saccade latencies but only for reactive saccades elicited by a gap interval of 100 or 200 $\mathrm{ms}$, with the effect being mainly because of a different proportion of express saccades. Finally, other work using reactive or voluntary saccades, such as memory-guided or antisaccades, did not find any differences in latencies for either the average $e^{7,8}$ or the individual data. ${ }^{8}$

More recently, the question of a potential role of eye dominance has been raised.9,10 The ocular dominance, also called "sighting dominance," is defined by the eye chosen by the subject when he or she is asked to align a target with a distant point. This is the usual sense of eye dominance described in the literature and this is not necessarily convergent with handedness. It should be distinguished from the sensory dominance, also called "ocular prevalence,"11 that refers to the fact that people give a higher weight to the input from one eye than to the input from the other eye, as well as from the acuity dominance that designates the eye showing the better measures of visual functioning. ${ }^{12}$ Motor, sensory, and acuity dominances can be evaluated with specific tests. Interestingly, for our purpose, recent works testing right-handers with left or right eye dominance argues 
for a potential role of eye dominance on hemispheric specialization for saccadic control, but again with contradictory results. The first study ${ }^{9}$ reported shorter latencies for leftward saccades in the right-eyed group and no difference for the left-eyed group. The second ${ }^{10}$ showed that, for the left-eyed group, latencies were shorter for leftward than rightward saccades; for the right-eyed group, the results were less clear, as latencies of rightward saccades tended only to be shorter.

Surprisingly, the possible occurrence of spatial asymmetry in parameters other than saccade latency has not been fully considered. Among the pioneering works that had determined saccadic parameters, without any reference to handedness, some had reported faster leftward saccadic velocities, ${ }^{13}$ whereas others found the reverse. ${ }^{14,15}$ In the same way, some had reported faster saccades in the temporal (abduction) than in the nasal (adduction) direction, ${ }^{15-18}$ even if the opposite pattern has also been reported. ${ }^{19,20}$ To our knowledge, only two studies with right-handed subjects raised this question. The first ${ }^{21}$ did not find any direction effect on saccade latency, duration, or average velocity. The second ${ }^{22}$ showed better accuracy for memory-guided saccades directed to the left than to the right, suggesting that the right hemisphere is superior at localizing visual targets.

The lack of consistent results makes it difficult to draw conclusions about the possible lateralization of oculomotor processes. Arguments in favor of the asymmetric control of saccades come from electrophysiological and imaging studies. For example, electrical stimulation of the superior colliculus and of the frontal eye field elicits saccades that are directed into the contralateral visual field. ${ }^{23-26}$ In humans, functional magnetic resonance imaging studies have shown that a leftsided network, including the supplementary eye field and the posterior parietal cortex, is involved in the generation of selfpaced saccades. ${ }^{27,28}$ Moreover, regardless of the saccade direction, the execution of visually guided saccades by righthanders involves right asymmetrical activations of visual and oculomotor areas that belong to the saccadic/attentional network, as well as left asymmetrical motor activations referring to the general dominance of the left motor cortex in right-handers. ${ }^{29}$ Interestingly, one study ${ }^{9}$ used an electroencephalogram to record presaccadic potentials in right-handers with left or right eye dominance during pro- and antisaccade tasks. The two eye groups differed with respect to the characteristics of slow potentials in the antisaccade task. Indeed, changes in the slow potentials during the last $50 \mathrm{~ms}$ before the execution of the saccade depended on its direction, reflecting the activation of the hemisphere opposite to the saccade direction. The activation of the right hemisphere before leftward saccades was greater in the left-eyed than in the right-eyed group, however, and was associated with a reduction in the frontal area and an increase in the left posterior temporal area of negative presaccadic potentials.

Thus, the question remains of whether or not hemispheric specialization exists for the saccadic system. Although some arguments are provided by imaging studies, experimental studies taking eye movement parameters as behavioral indicators have failed to establish a coherent picture of the situation. Most of them have focused on saccade latency, and it is difficult to compare their results because of methodological differences: the nature of the tested saccade (reactive versus voluntary), the target eccentricities inducing small or large saccades, the initial fixation position (central or peripheral), or the absence of reference to eye and even sometimes to hand dominance. In this study, we conducted a systematic investigation of the latency, gain, and peak velocity of reactive and voluntary saccades, taking eye and hand dominance into account.

\section{Methods}

\section{Subjects}

Forty-five participants were divided into four groups according to their hand and ocular dominance. Seventeen were right-handed with righteye dominance (RE-RH; 1 male [M], 16 female [F]; mean age: 22.4, SD: 3.89 ; mean laterality score: $93.57 \%$, SD: $3.98 \%$, range: $88.36 \%$ to $100 \%$ ). Twelve were right-handed with left-eye dominance (LE-RH; 3M 9F; mean age: 28.4 , SD: 6.53 ; mean laterality score: $85.97 \%$, SD: $5.8 \%$, range: $77.27 \%$ to $95.45 \%$ ). Eleven were left-handed with left-eye dominance (LE-LH; 2M 9F; mean age: 28.64, SD: 7.49; mean laterality score: $18.18 \%$, SD: $11.67 \%$, range: $4.55 \%$ to $34.09 \%$ ), and five were lefthanded with right-eye dominance (RE-LH; 4M 1F; mean age: 26.60, SD: 7.99; mean laterality score: $35.32 \%$, SD: $24.38 \%$, range: $11.36 \%$ to $63 \%$ ). Their hand preference was determined by using the Humphrey Laterality Questionnaire modified by Hécaen and Ajuriaguerra ${ }^{30}$ (22 items testing hand, eye, and foot preferences). Their ocular dominance was determined by using the "telescope" test in which subjects were asked to look through a tube, and the eye chosen by the subject was considered as dominant. All of the participants had normal or corrected to normal vision. Six of them (three were authors of this article) were familiar with eye movement recording. All gave their informed consent after an explanation of the procedure. The study adhered to the principles of the Declaration of Helsinki.

\section{Stimuli}

The initial central fixation cross and the saccade target were $0.5^{\circ} \times 0.5^{\circ}$ white crosses displayed on a medium gray background. The saccade target could appear $5^{\circ}, 10^{\circ}$, or $15^{\circ}$ to the left or to the right of the fixation cross.

\section{Instruments and Eye Movement Recording}

Stimuli were presented on an liyama HM240DT monitor (Iiyama, Nagano, Japan) with a refresh rate of $170 \mathrm{~Hz}$ and a resolution of $800 \times$ 600 pixels. The experimental sessions took place in a dimly lit room. Subjects were seated $57 \mathrm{~cm}$ away from the screen and their heads kept stable with a chin and forehead rest. Eye movements were recorded with an Eyelink 1000 (SR Research, Ontario, Canada), with a temporal resolution of $1000 \mathrm{~Hz}$, and a spatial resolution of $0.25^{\circ}$. In the experiment, viewing was binocular but only movements of the dominant eye were monitored. Additional binocular recordings were performed for some participants.

Each session began with a nine-point calibration over the entire screen. Before each trial, a small circle was presented at the screen center to compare the actual eye position with the previous calibration. The participants had to fixate the circle and to press a button of the pad. If successful comparison was detected, the trial began. Online saccade detection corresponded to above-threshold velocity $\left(30^{\circ} / \mathrm{s}\right)$ and acceleration $\left(8000^{\circ} / \mathrm{s}^{2}\right)$.

\section{Procedure}

In separate sessions, procedures known to induce reactive or voluntary saccades were used. Each trial of each session began by the presentation of the initial fixation cross randomly displayed during 400,600 , or $800 \mathrm{~ms}$. During this delay, the eye position was checked and if the distance between eye position and the center of the cross was greater than $0.75^{\circ}$, the trial was cancelled and returned later in the session. In two tasks, prosaccades were elicited; the subject had to saccade to the target when the fixation cross disappeared. The initial fixation cross disappeared $200 \mathrm{~ms}$ before the target appeared (Gap200) or at the same time (Gap-0), eliciting reactive saccades. In a third task, the procedure was similar: after the random delay of the fixation cross presentation, the target was displayed and the fixation cross disappeared $600 \mathrm{~ms}$ after that (Overlap-600). This task elicited 
voluntary saccades, as participants were instructed to differ their saccade to the target until the offset of the fixation point. Note that the eye position was also checked during the overlap delay. Finally, in the voluntary Antisaccade task, the target appeared simultaneously with the disappearance of the fixation cross, as in the Gap-0 ms condition, but the subject was asked to initiate a saccade to the mirror location of the target. Each subject performed 90 trials per session. The saccade task order was randomized across subjects. In each session, the target was displayed at $5^{\circ}, 10^{\circ}$, or $15^{\circ}$ left or right, 15 times each, in a random order.

\section{Results}

We discarded from further analysis trials with the occurrence of blinks (0.06\%); eye movement in the wrong direction relative to the task ( $4.7 \%$ in the antisaccade task, $0.29 \%$ in the three other saccade tasks); and latency, amplitude, or peak velocity outliers differing from 2 SDs relative to the mean (3.98\%).

Table 1 presents the mean leftward and rightward saccade latency (ms), gain (saccade amplitude/target eccentricity ratio), and peak velocity $(\%)$ for each eccentricity of each saccade task in the four groups of subjects. An ANOVA was run for each measure with eye and hand dominance as betweensubject factors and saccade task, saccade direction, and target eccentricity as within-subject factors. Because our objective was to investigate possible motor asymmetries, we focused mainly on the saccade direction effect on average latency, gain, and peak velocity. At the individual level, we computed the difference between average rightward and leftward saccades (RS-LS) in each condition resulting from the crossing of saccade task and target eccentricity. A negative difference for latency, gain, and peak velocity means that leftward saccades have longer latencies, larger sizes, and greater peak velocities than rightward saccades. Figures $1 \mathrm{a}, 2 \mathrm{a}$, and $3 \mathrm{a}$ present the average RS-LS differences for these dependent variables for the four groups of subjects. Note that this corresponds with the saccade direction effect tested in the ANOVA for each group in each experimental condition. Individual differences for each group are shown in Figures $1 \mathrm{~b}, 2 \mathrm{~b}$, and $3 \mathrm{~b}$. We performed comparisons at the individual level using a paired, two-tailed Student's $t$-test; the number of subjects showing a significant effect $(P<0.05)$ is given in parentheses.

As expected with our procedures, we found a main effect of saccade task on the average saccade latency $\left(F_{(3,123)}=137.94\right.$, $P<0.0001)$, which increased from the Gap-200 (177 $\pm 10 \mathrm{~ms})$ to the Gap-0 (199 $\pm 7 \mathrm{~ms})$, Overlap-600 (242 $\pm 17 \mathrm{~ms})$, and Antisaccade $(297 \pm 16 \mathrm{~ms})$ tasks. More interestingly, we did not find any effect of saccade direction $(228 \pm 49 \mathrm{~ms}$ vs. 230 $\pm 47 \mathrm{~ms}$ for leftward and rightward saccades, respectively, $F<$ 1) or dominant eye $(231 \pm 52 \mathrm{~ms}$ and $227 \pm 44 \mathrm{~ms}$ for left-eye and right-eye dominance, respectively, $F<1$ ). However, an effect of target eccentricity appeared $\left(F_{(2,82)}=23.44, P<\right.$ $0.0001)$; it interacted with saccade task and dominant eye $\left(F_{(6,246)}=2.92, P<0.009\right)$. This interaction indicates that, for subjects with left-eye dominance, the reactive saccade latency was longer for saccades directed to the $15^{\circ}$ target compared with the $5^{\circ}$ and $10^{\circ}$ targets (Gap-200: difference of $18 \mathrm{~ms}$, $F_{(1,21)}=49.80, P<0.0001$; Gap-0: $10.5 \mathrm{~ms}, F_{(1,21)}=29.97, P<$ $0.0001)$. This kind of difference did not reach significance in the Overlap-600 task $\left(6 \mathrm{~ms}, F_{(1,21)}=3.43, P<0.07\right)$ and was not found in the Antisaccade task $(F<1)$. Finally, latencies were slightly longer for right-handers than for left-handers but the difference was marginal $\left(F_{(1,41)}=3.46, P<0.07\right)$. In line with the lack of saccade direction effect and of any interaction with this factor, the individual RS-LS differences computed for the saccade latency did not reveal any clear pattern (see Fig. 1b). A given participant could experience faster triggering for rightward saccades in some conditions and faster triggering for leftward saccades in others. No consistent differences across conditions were found in the 45 participants.

Concerning the saccade gain, we did not find any effect of saccade task or eye dominance $\left(F<1 ; F_{(1,41)}=2.51\right.$, NS, respectively). Right-handers slightly undershot the target, whereas left-handers had precise saccadic gain $(0.94 \pm 0.13$ vs. $1 \pm 0.25)$; however, the difference failed to reach significance $\left(F_{(1,41)}=3.8, P<0.06\right)$. As has previously been shown, ${ }^{31,32}$ the saccade overshot the closest target and undershot more distant targets $(1.11 \pm 0.28,0.94 \pm 0.07$, and $0.87 \pm 0.12$ for $5^{\circ}, 10^{\circ}$, and $15^{\circ}$, respectively, $F_{(2,82)}=$ 213.25, $P<0.0001)$. Interestingly, the saccade direction effect was significant; rightward saccades were more accurate than leftward saccades, as their gain was closer to 1 , which corresponded to a perfect aim of the saccade target $(0.98 \pm$ 0.22 vs. $0.96 \pm 0.19$, respectively, $\left.F_{(1,41)}=13.98, P<0.0006\right)$. However, as we found an interaction among the five main factors $\left(F_{(6,246)}=2.18, P<0.04\right)$, we examined the saccade direction effect by groups of participants. The saccade direction effect was clearly found only for the RE-RHs (all $P$ $<0.008$ for each eccentricity of the three first saccade tasks; $P$ $<0.07$ for the $5^{\circ}$ target and NS for the $10^{\circ}$ and $15^{\circ}$ targets in the antisaccade task; see Fig. 2a). For this group, rightward saccades were larger than leftward saccades, leading to better accuracy. The individual RS-LS differences shown in Figure 2b confirm that, for RE-RHs, rightward saccades were larger than leftward saccades in the great majority of experimental conditions except in the Antisaccade task (individual T-tests $P<0.05$ : Gap-200: 7 subjects/17, 8/17, $9 / 17$ for the $5^{\circ}, 10^{\circ}$, and $15^{\circ}$ targets; Gap-0: 10/17, 9/17, 12/17; Overlap-600: 9/17, 13/17, 9/17; Antisaccade: 3/17, 5/17, 6/17). However, Figure $2 \mathrm{~b}$ reveals that, despite the lack of saccade direction effect on the ANOVA run on saccadic gain, the same tendency appeared in the RE-LHs, as four of the five subjects showed consistently larger rightward saccades. Note, however, that this effect failed to reach significance in some conditions (Gap-200: 2/5, 4/5, 4/ 5 for the $5^{\circ}, 10^{\circ}$, and $15^{\circ}$ targets; Gap-0: $1 / 5,2 / 5,4 / 5$; Overlap600: 2/5, 4/5, 2/5; Antisaccade: $2 / 5,2 / 5,2 / 5$ ). In the left-eyed participants, regardless of their hand dominance, no consistent pattern appeared; some subjects had larger rightward saccades, whereas others had larger leftward ones.

Finally, the ANOVA run on the average peak velocity did not show any effect of hand or eye dominance $\left(F<1\right.$ and $F_{(1,41)}=$ 2.51 , NS) but revealed a main effect of target eccentricity and of saccade task $\left(F_{(2,82)}=862, P<0.0001 ; F_{(3,123)}=47.47, P<\right.$ 0.0001 , respectively). The peak velocity that increased with saccade size was similar for reactive saccades (Gap-0 and Gap200: $329 \pm 65^{\circ} / \mathrm{s}$ and $333 \pm 65^{\circ} / \mathrm{s}$ respectively) and slower for voluntary saccades, in particular in the Antisaccade task (Overlap-600: $313 \pm 60^{\circ} / \mathrm{s}$ and Antisaccade: $290 \pm 32^{\circ} / \mathrm{s}$ ). The effect of the saccade direction failed to reach significance $\left(312 \pm 55^{\circ} / \mathrm{s}\right.$ vs. $321 \pm 63^{\circ} / \mathrm{s}$ for leftward and rightward saccades, respectively, $F_{(1,41)}=2.22$, NS) but interacted with eye dominance, hand dominance, and target eccentricity $\left(F_{(2,82)}=6.81, P<0.001\right)$. Interestingly for our purpose, the effect of saccade direction was reversed between right-eyed and left-eyed groups, irrespective of their hand dominance. For right-eyed participants, the mean peak velocity was greater for rightward saccades than for leftward saccades (RE-RH: $F_{(1,16)}=$ 26.15, $P<0.0001, F_{(1,16)}=16.91, P<0.0008$, and $F_{(1,16)}=$ 20.05, $P<0.0004$, for $5^{\circ}, 10^{\circ}$, and $15^{\circ}$; RE-LH: $F_{(1,4)}=9.46, P<$ $0.03, F_{(1,4)}=20.85, P<0.01$, and $F_{(1,4)}=10.7, P<0.03$, for $5^{\circ}$, $10^{\circ}$, and $15^{\circ}$ ). For left-eyed participants, the mean peak velocity was greater for leftward saccades than for rightward saccades (LE-RH: $F_{(1,12)}=11.99, P<0.05, F_{(1,11)}=11.61, P<$ 0.005 , and $F_{(1,11)}=12.60, P<0.004$, for $5^{\circ}, 10^{\circ}$, and $15^{\circ}$; LE- 


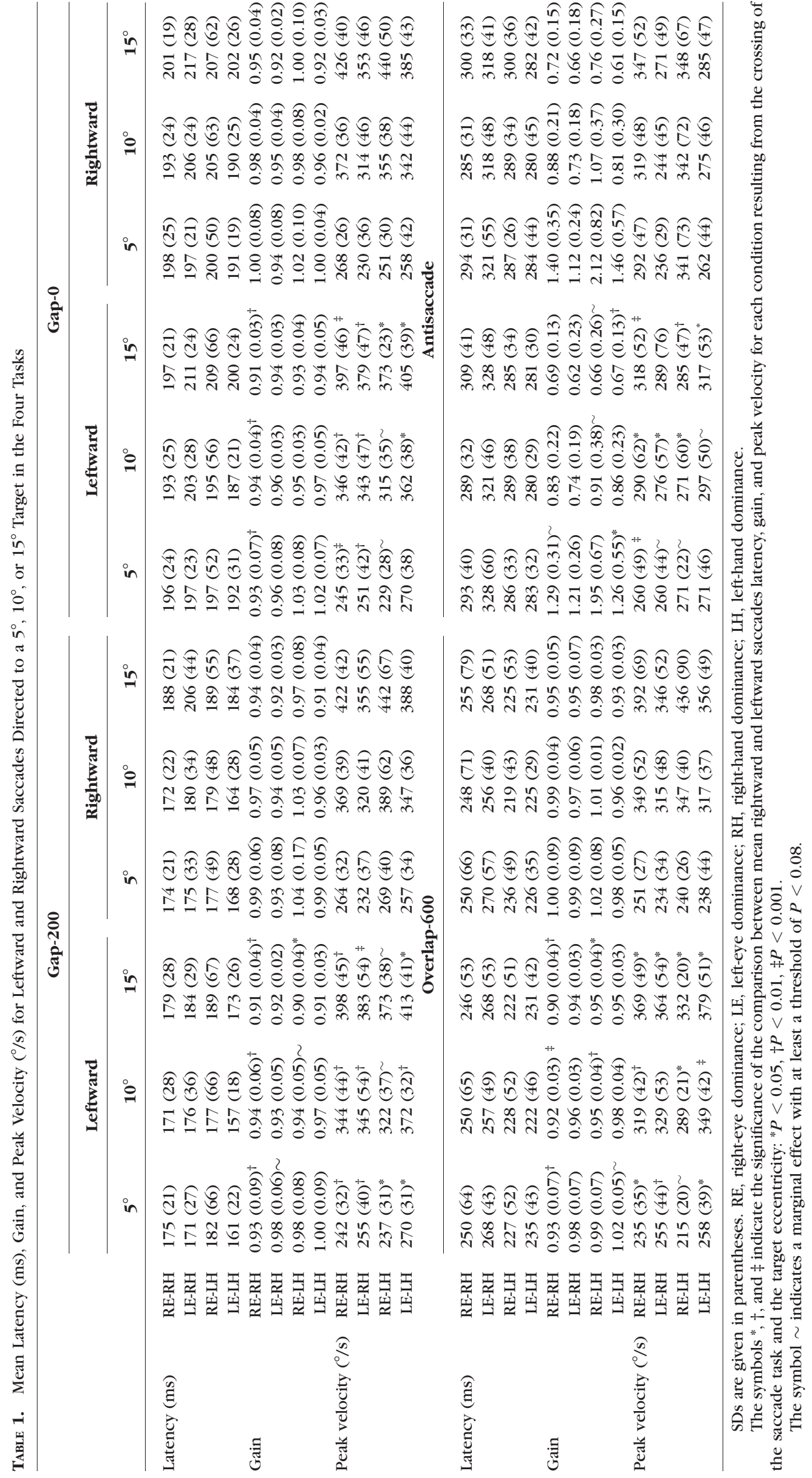



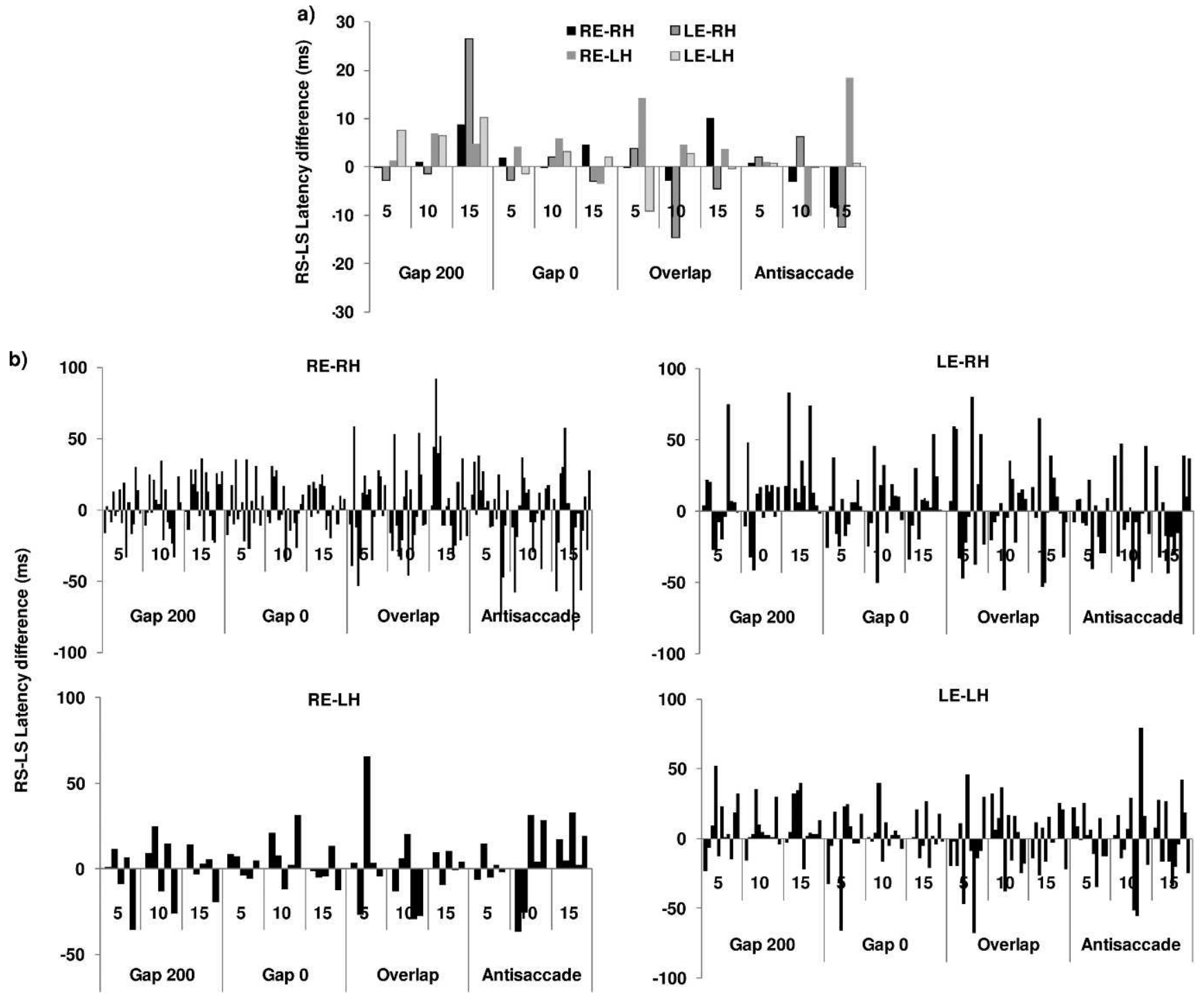

Figure 1. (a) Average differences between rightward and leftward saccade latency (milliseconds) for the four groups of subjects: RE-RH, LE-RH, RELH, and LE-LH. Differences are shown for each target eccentricity and each saccade task. Negative differences for latency mean that leftward saccades have longer latencies than rightward saccades; a positive difference indicates the reverse. The symbol " $\sim$ " indicates a marginal difference with a threshold between $P<0.08$ and $P<0.05$. The asterisk indicates a significant difference, precise thresholds are given in Table 1 . (b) Individual RS-LS latency differences for each group of subjects contrasted by their eye and hand dominance. Right-eyed groups were presented in the left column, left-eyed groups in the right column.

LH: $F_{(1,10)}=4.17, P<0.06, F_{(1,10)}=13.59, P<0.004$, and $F_{(1,10)}=10.94, P<0.007$, for $5^{\circ}, 10^{\circ}$, and $\left.15^{\circ}\right)$. Although the interaction among the five factors was not significant $(F<1)$, we examined the group comparisons for each eccentricity and each saccade task (see Fig. 3b). The effect of saccade direction was consistently found for the RE-RHs (all $P<0.04$ ), the LELHs (all $P<0.04$, except NS for $5^{\circ}$ Gap-0; marginal for $5^{\circ}$ and $10^{\circ}$ Antisaccade), and the LE-RHs (all $P<0.02$, except NS for $10^{\circ}$ Overlap-600; marginal for $5^{\circ}$ and $15^{\circ}$ Antisaccade). Despite the small number of subjects in the RE-LH group, the effect of saccade direction was significant in half of the conditions (all $P$ $<0.05$ ) and marginal in the other half (all $P<0.08$ ). The examination of individual RS-LS differences clearly showed that both right-eyed groups had faster saccades toward the right than to the left (Fig. 3b: RE-RH: Gap-200: 12/17, 12/17, 11/17 for the $5^{\circ}, 10^{\circ}$, and $15^{\circ}$ target; Gap-0: 14/17, 12/17, 13/17; Overlap-600: 11/17, 10/17, 11/17; Antisaccade: 11/17, 10/17, 11/17; RE-LH: Gap-200: 4/5, 5/5, 5/5; Gap-0: 4/5, 3/5, 5/5; Overlap-600: 4/5, 4/5, 5/5; Antisaccade: 3/5, 4/5, 4/5), whereas both left-eyed groups had faster saccades toward the left than the right (Fig. 1b: LE-RH: Gap-200: 7/12, 7/12, 8/12; Gap-0: 8/12, 8/12, 6/12; Overlap-600: 5/12, 6/12, 5/12; Antisaccade: 1/12, 2/12, 2/12; LE-LH: Gap-200: 7/11, 8/11, 6/ 11; Gap-0: 6/11, 7/11, 7/11; Overlap-600: 5/11, 10/11, 6/11; Antisaccade: 4/11, 6/11, 6/11).

To summarize our results, left-right asymmetries appeared in saccade gain and peak velocity rather than on saccade latency. Indeed, rightward saccades were larger than leftward saccades for RE-RHs, with the same tendency for RE-LHs. Moreover, individual and averaged data consistently show that, regardless of dominant hand, both right-eyed groups made faster rightward saccades, whereas both left-eyed groups made faster leftward saccades. So, one can conclude that the saccades directed in the ipsilateral direction relative to the dominant eye sometimes had larger amplitudes and definitely had faster peak velocities, suggesting that eye dominance is the main factor in this asymmetry. However, rightward saccades of the right-eyed groups and leftward saccades of the left-eyed 

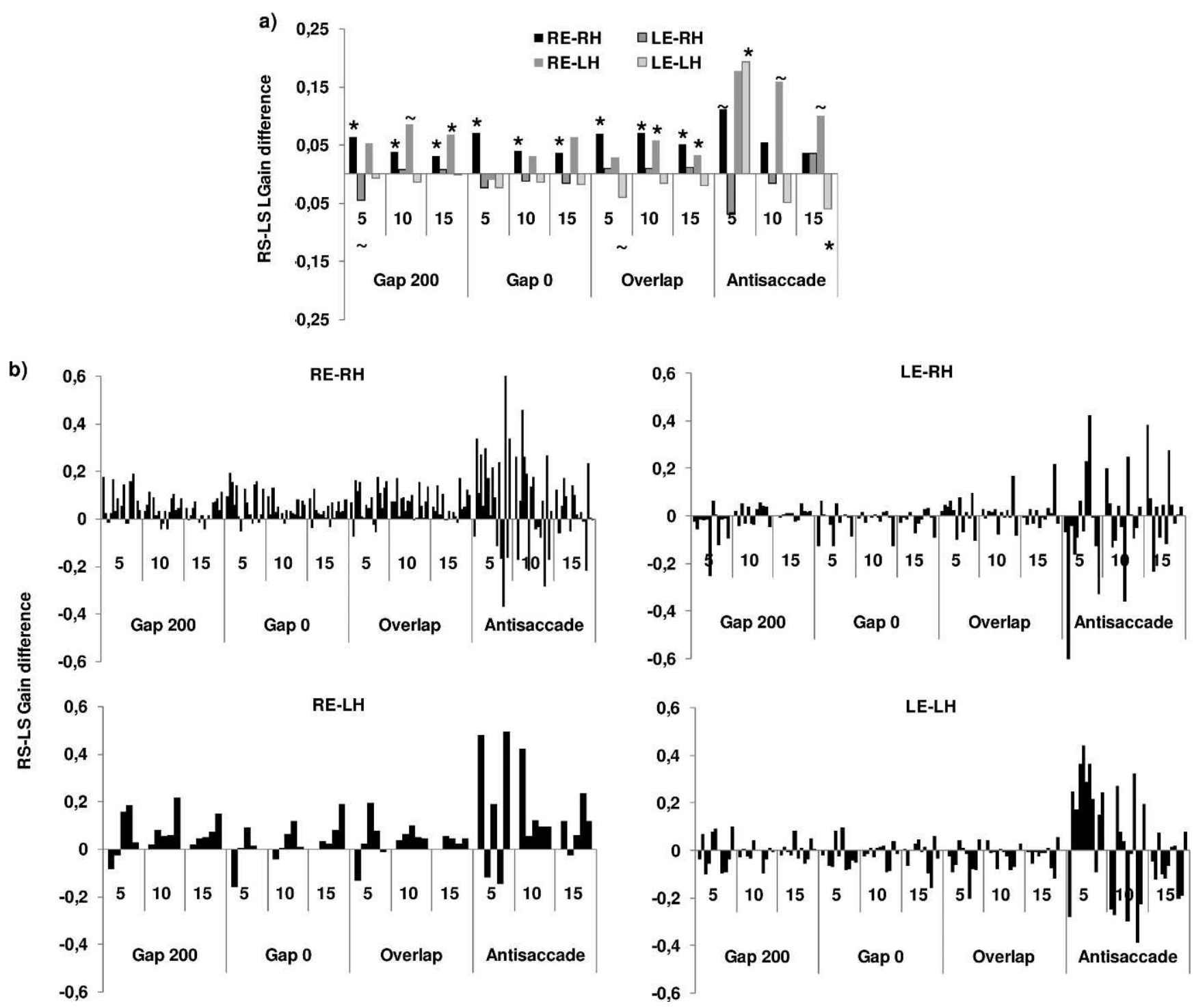

Figure 2. (a) Average differences between rightward and leftward saccade gain for the four groups of subjects. Differences are shown for each target eccentricity and each saccade task. Negative differences mean that leftward saccades have larger sizes than rightward saccades; a positive difference indicates the reverse. The symbol " " indicates a marginal difference with a threshold between $P<0.08$ and $P<0.05$. The asterisk indicates a significant difference; precise thresholds are given in Table 1. (b) Individual RS-LS gain differences for each group of subjects contrasted by their eye and hand dominance. Right-eyed groups were presented in the left column, left-eyed groups in the right column.

groups are all centrifugal and executed in the temporal direction by the abducting eye. Thus, the observed difference could perhaps be explained by abducting-adducting or nasotemporal asymmetries rather than by a relationship with eye dominance. ${ }^{15-20}$ As the monocular recording used here prevents us from distinguishing between the two explanations, we completed the experiment by asking some participants to run again the Gap-0 and Overlap-600 tasks again with binocular recording. This was done with five RE-RHs, six LE-RHs, two RELHs, and five LE-LHs. We focused on the peak velocity data, as the effects of the saccade direction clearly appeared on this dependent variable for monocular recordings. We reasoned that, if the left-right asymmetry was explained by eye dominance, we should find a similar effect regardless of the eye recorded (dominant or nondominant). For a right-eyed observer, rightward saccades executed by the left or right eye should always be faster, whereas for a left-eyed observer, leftward saccades should be faster. Alternatively, if the asymmetry was explained by a naso-temporal effect, then rightward saccades of the right eye and leftward saccades of the left eye should be faster, irrespective of eye dominance. The individual RS-LS peak velocity differences for each subject of each group presented in Figure 4 show that the eye dominance hypothesis is supported by the results of two RERHs (subject 1 [s1] and s2), one LE-RH (s1), and three LE-LHs (s1, s2, and s3), whereas the naso-temporal explanation is supported by the results of two RE-RHs ( 44 and s5), one RE-LHs (s2), four LE-RHs (s3, s4, s5, and s6), and two LE-LHs (s4, s5). Note that subject 1 of the RE-LH group did not have a clear pattern. More interestingly, two subjects (s3 in the RE-RH group and s2 in the LE-RH) fit with the ocular dominance hypothesis but with the pattern corresponding to their nondominant eye: the RE-RH s3 had faster leftward saccades, whereas the LE-RH s2 had faster rightward saccades, irrespective of the recorded eye. Their patterns are similar for binocular as well as for monocular recording. As discussed later, these results raise the question of whether the test used to determine ocular dominance are adapted, as they force 
a)

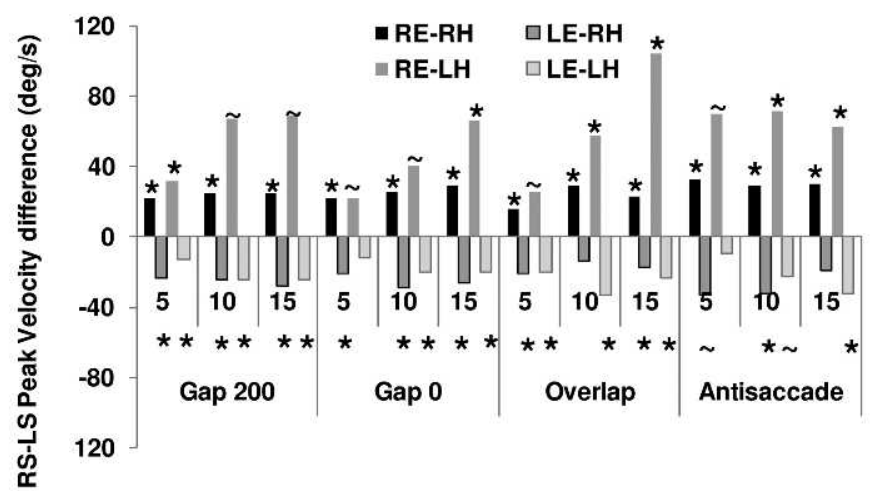

b)

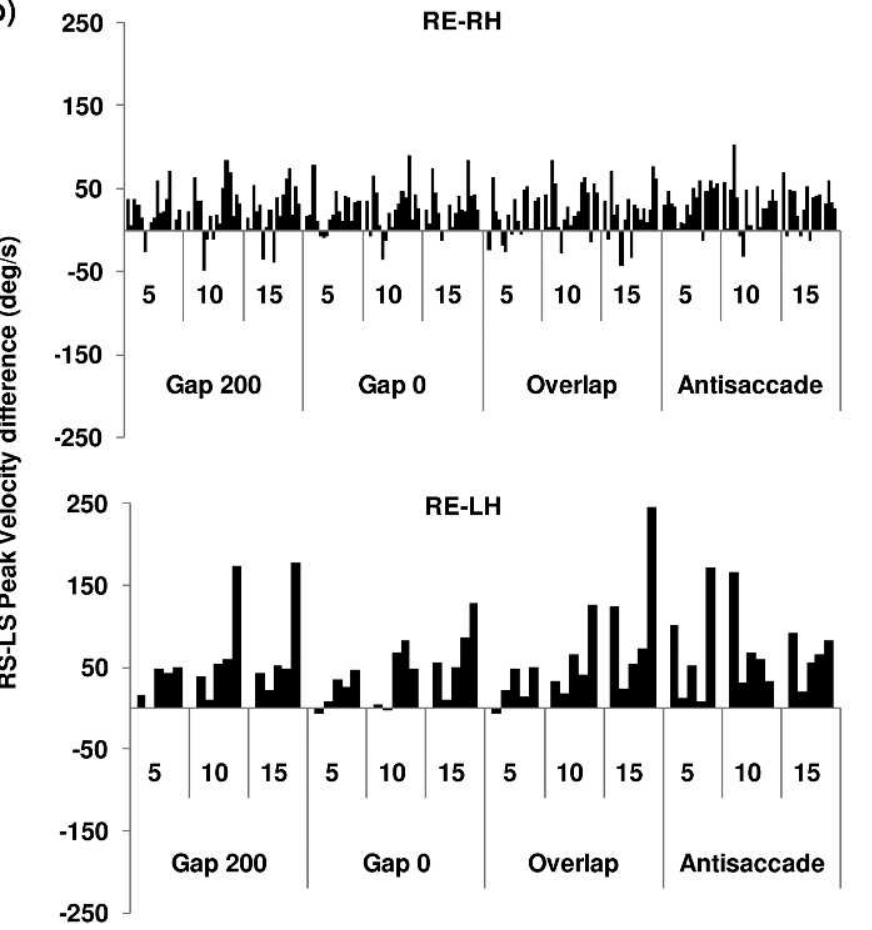

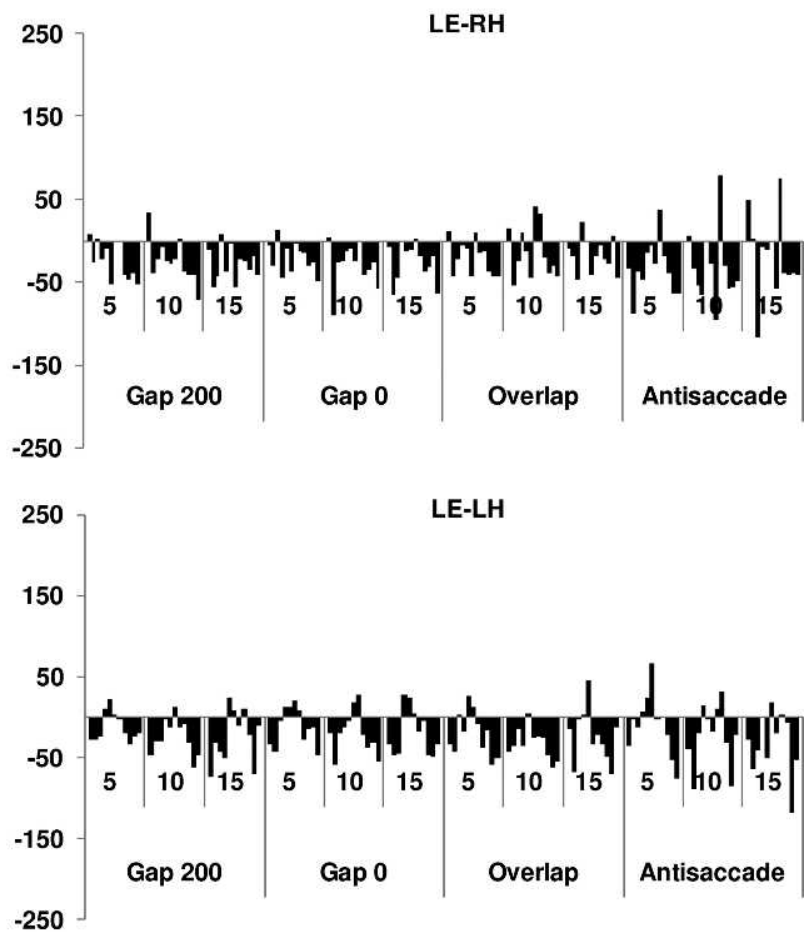

Figure 3. (a) Average differences between rightward and leftward saccade peak velocity $(\%)$ for the four groups of subjects. Differences are shown for each target eccentricity and each saccade task. Negative differences for peak velocity mean that leftward saccades have greater peak velocities than rightward saccades; a positive difference indicates the reverse. The symbol " $\sim$ " indicates a marginal difference with a threshold between $P<0.08$ and $P<0.05$. The asterisk indicates a significant difference; precise thresholds are given in Table 1. (b) Individual RS-LS differences for each group of subjects contrasted by their eye and hand dominance. Right-eyed groups were presented in the left column, left-eyed groups in the right column.

participants to choose one eye and so does not take into consideration that some people did not have a clear ocular dominance.

\section{Discussion}

Similar to previous studies, ${ }^{7,8,21}$ we found no evidence in favor of left-right asymmetries in saccade latency. This contrasts with previous work showing different temporal asymmetry for righthanders $^{3,4}$ relative to their eye dominance. ${ }^{9,10}$ However, as noted in the introductory paragraphs, differences in many methodological points make it difficult to interpret this discrepancy. Here, we have systematically investigated leftright asymmetries by manipulating the type of saccade (reactive versus voluntary), target eccentricity, and manual/ ocular dominance. Neither the averaged nor the individual data revealed any effect of saccade direction on latencies; however, left-right asymmetries appeared in saccade gain and peak velocity. Rightward saccades were larger than leftward saccades for RE-RHs, with the same tendency for RE-LHs. Moreover, regardless of the dominant hand, both right-eyed groups made faster rightward saccades, whereas both left-eyed groups made faster leftward saccades. Binocular recordings were conducted to determine whether these left-right asymmetries were linked to the ocular dominance or more simply explained by the abducting-adducting or naso-temporal asymmetries. However, the results of binocular recording indicated that some participants fit with the ocular dominance hypothesis whereas others fit with the naso-temporal/abductionadduction hypothesis.

How can we explain these two consistent patterns of data? One possibility is to consider that, as supported by previous studies, clear ocular dominance can be found only in some people, whereas others may present an alternating balance 

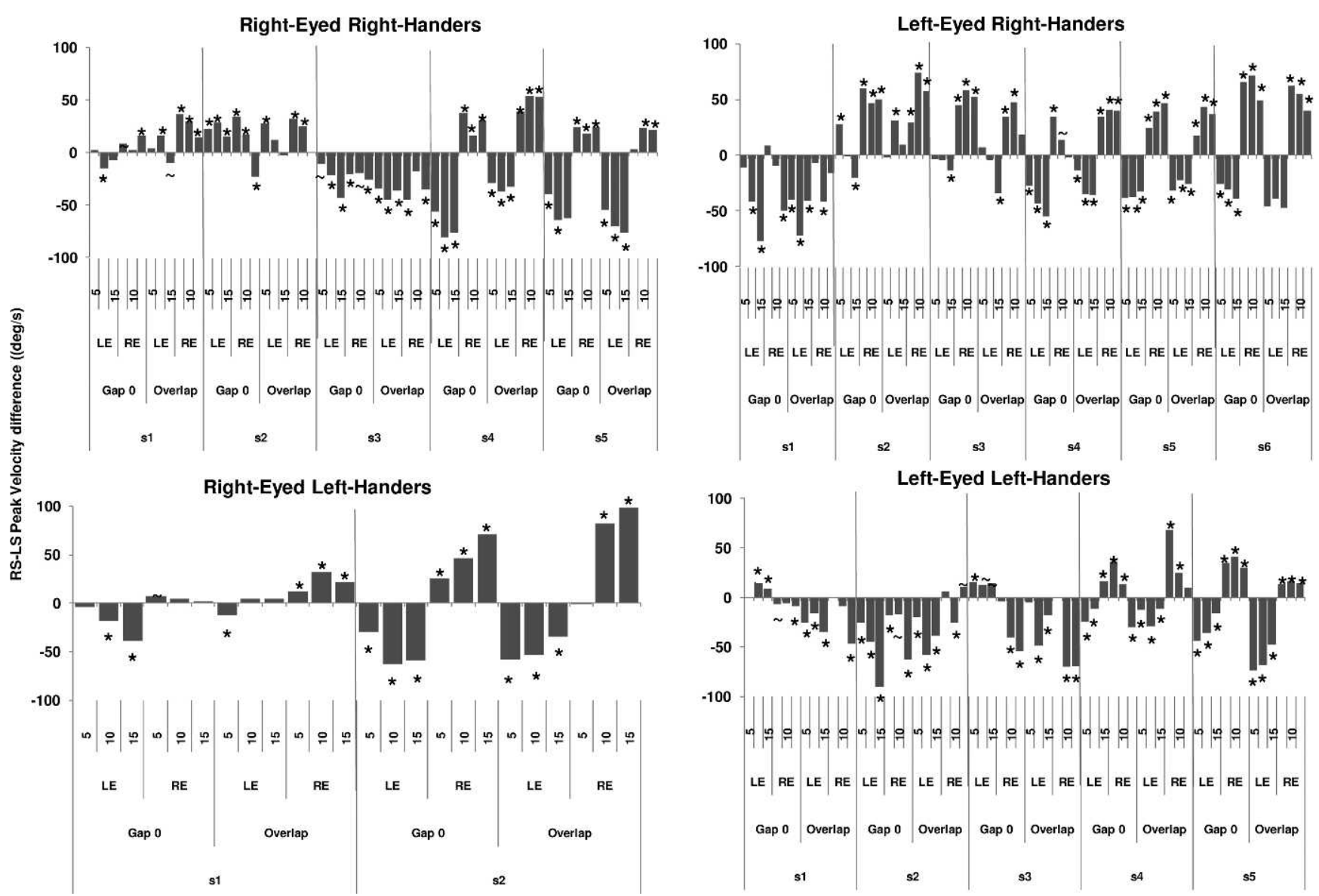

Figure 4. Individual differences between rightward and leftward saccade peak velocity (in \% $/ \mathrm{s}$ ) for five RE-RHs, six LE-RHs, two RE-LHs, and five LELHs. Recording was binocular and data were presented to both eyes of each subject performing $5^{\circ}, 10^{\circ}$, and $15^{\circ}$ saccades in the Gap-0 and Overlap600 tasks. Individual comparisons were performed with Student's $t$-tests. The asterisk indicates a significant difference with a threshold inferior to $P$ $<0.05$; the symbol " $\sim$ " indicates a marginal difference with a threshold between $P<0.10$ and $P<0.05$.

between both eyes. ${ }^{12,33}$ This interindividual variability raises the question of the pertinence of the tests used to determine ocular dominance. As they force participants to choose one eye, they can be considered as "all or nothing" tests that are not suited to quantify the ocular dominance of participants that such tests of handedness can do with manual laterality by giving a percentage. Moreover, an intraindividual variability also exists, as ocular dominance has been found to be more plastic than hand or foot dominance. ${ }^{12,34}$ For example, it can change from one eye to the other depending on the gaze angle. ${ }^{35}$

So, does ocular dominance tell us anything about hemispheric specialization for oculomotor processes? A link might be dismissed, based on the argument that the brain network is not lateralized for the eyes. Visual afferences from one eye are projected to both hemispheres, whereas efferent signals to the muscles of one eye originate in different hemispheres, relative to the saccade direction. Recent imaging studies argue for some anatomical asymmetries, however, as eye dominance affects the laterality of activity in the visual cortex. ${ }^{8,29,30}$ Thus, the stimulation of the dominant eye evokes more widespread activation with a shorter latency in occipital cortical areas than the stimulation of the other eye. ${ }^{36,37}$ More recently, it has been shown that ocular dominance is predominantly regulated by the ipsilateral occipital cortex. ${ }^{38,39}$

In this study, we show left-right asymmetries on saccadic gain and peak velocity. From a methodological point of view, it appears important to take this result into consideration before pooling data across the two saccade directions, as is commonly done in most studies. We also show that, at least for some people, ocular dominance can explain this left-right asymmetry. However, further research is needed to investigate more systematically the saccadic parameters when dominant and nondominant eyes are recorded. ${ }^{40}$ Any method that helps to determine ocular dominance from objective measures based on saccade parameters should greatly benefit clinical applications, such as monovision surgery. ${ }^{33}$

\section{References}

1. Dien J. Looking both ways through time: the Janus model of lateralized cognition. Brain Cogn. 2008;67:292-323.

2. Serrien DJ, Ivry RB, Swinnen SP. Dynamics of hemispheric specialization and integration in the context of motor control. Nat Rev Neurosci. 2006;7:160-167.

3. Pirozzolo FJ, Rayner K. Handedness, hemispheric specialization and saccadic eye movement latencies. Neuropsychologia. 1980;18:225-229.

4. Hutton JT, Palet J. Lateral saccadic latencies and handedness. Neuropsychologia. 1986;24:449-451.

5. Honda H. Idiosyncratic left-right asymmetries of saccadic latencies: examination in a gap paradigm. Vision Res. 2002;42: $1437-1445$.

6. Weber H, Fischer B. Gap duration and location of attention focus modulate the occurrence of left/right asymmetries in the 
saccadic reaction times of human subjects. Vision Res. 1995; 35:987-998.

7. De Clerck M, Crevits L, Van Maele G. Saccades: is there a difference between right and left? Neuro-Ophthalmol. 2000; 24:327-330.

8. Constantinidis TS, Smyrnis N, Evdokimidis I, et al. Effects of direction on saccadic performance in relation to lateral preferences. Exp Brain Res. 2003;150:443-448.

9. Lazarev IE, Kirenskaya AV. The influence of eye dominance on saccade characteristics and slow presaccadic potentials. Hum Physiol. 2008;34:150-160.

10. Kolesnikova OV, Tereshchenko LV, Latanov AV, Shulgovskii VV. Effects of visual environment complexity on saccade performance in humans with different functional asymmetry profiles. Neurosci Behav Physiol. 2010;40:869-876.

11. Kommerell G, Schmitt, C, Kromeier M, Bach M. Ocular prevalence versus ocular dominance. Vis Res. 2003;43:13971403.

12. Mapp AP, Ono $H$, Barbeito $R$. What does the dominant eye dominate? A brief and somewhat contentious review. Percept Psychophys. 2003;65:310-317.

13. Dodge R, Cline TS. The angle velocity of eye movements. Psychol Rep. 1901;8:145-157.

14. Travis RC. The latency and velocity of the eye in saccadic movements. Psychol Monogr. 1936;47:242-249.

15. Hyde JE. Some characteristics of voluntary human ocular movements in the horizontal plane. Am J Ophthalmol. 1959; 48:85-94.

16. Robinson DA. The mechanics of human saccadic eye movement. J Physiol. 1964;174:245-264.

17. Fricker SJ. Dynamic measurements of horizontal eye motion, acceleration and velocity matrices. Invest Ophthalmol. 1971; 10:724-732.

18. Collewijn H, Erkelen CJ, Steinman RM. Binocular co-ordination of human horizontal saccadic eye movements. J Physiol. 1988; 404:157-182.

19. Boghen D, Troost BT, Daroff LF, Dell'Osso LF, Birkett JE. Velocity characteristics of normal human saccades. Invest Ophth. 1974;13:619-623.

20. Miyoshi T, Hiwatashi S, Kishimoto S, Tamada A. Dissociation of the eyes in saccadic movement. Ann N Y Acad Sci. 1981;374: 731-743.

21. Beydagi H, Yilmaz A, Süer C. The effect of direction on saccadic eye movement parameters. J Basic Clin Physiol Pharmacol. 1999;10:73-77.

22. Bracewell RM, Husain M, Stein JF. Specialization of the right hemisphere for visuomotor control. Neuropsychologia. 1990; 28:763-775.

23. Schiller PH, True SD, Conway JL. Paired stimulation of the frontal eye fields and the superior colliculus of the rhesus monkey. Brain Res. 1979;179:162-164.
24. Wurtz RH, Albano JE. Visual-motor function of the primate superior colliculus. Annu Rev Neurosci. 1980;3:189-226.

25. Bruce CJ, Goldberg ME. Physiology of the frontal eye fields. Trends Neurosci. 1984;7:436-441.

26. Bruce CJ, Goldberg ME, Bushnell MC, Stanton GB. Primate frontal eye fields. II. Physiological and anatomical correlates of electrically evoked eye movements. J Neurophys. 1985;54: 714-734.

27. Grosbras MH, Lobel E, Van de Moortele PF, LeBihan D, Berthoz A. An anatomical landmark for the supplementary eye fields in human revealed with functional magnetic resonance imaging. Cereb Cortex. 1999;9:705-711.

28. Khonsari RH, Lobel E, Milea D, Lehéricy S, Pierrot-Deseilligny C, Berthoz A. Lateralized parietal activity during decision and preparation of saccades. Neuroreport. 2007;18:1797-1800.

29. Petit L, Zago L, Vigneau M, et al. Functional asymmetries revealed in visually-guided saccades: an fMRI study. $J$ Neurophysiol. 2009;102:2994-3003.

30. Hécaen H, Ajuriaguerra J. Les Gauchers: Prevalence Manuelle et Dominance Cerebrale. Paris: UF; 1963.

31. Kapoula Z. Evidence for a range effect in the saccadic system. Vision Res. 1985;25:1155-1157.

32. Kapoula Z, Robinson DA. Saccadic undershoot is not inevitable: saccades can be accurate. Vision Res. 1986;26: 735-743.

33. Seijas O, Gomez de Liano P, Gomez de Liano R, Roberts CJ, Piedrahita E, Diaz E. Ocular dominance diagnosis and its influence in monovision. Am J Ophthalmol. 2007;144:209216.

34. Carey DP. Losing sight of eye dominance. Curr Biol. 2011;11: R828-R830.

35. Khan AZ, Crawford JD. Ocular dominance reverses as a function of horizontal gaze angle. Vis Res. 2001;41:17431748.

36. Rombouts SA, Barkhof F, Sprenger M, Valk J, Scheltens P. The functional basis of ocular dominance: functional MRI (fMRI) findings. Neurosci Lett. 1996;221:1-4.

37. Seyal M, Sato S, White BG, Porter RJ. Visual evoked potentials and eye dominance. Electroencephalogr Clin Neurophysiol. 1981;52:424-428.

38. Erdogan AR, Ozdikici M, Aydin MD, Aktas O, Dane S. Right and left visual cortex areas in healthy subjects with right-eye and left-eye dominance. Int J Neurosci. 2002;112:517-523.

39. Shima H, Hasegawa M, Tachibana O, et al. Ocular dominance affects magnitude of dipole moment: an MEG study. Neuroreport. 2010;21:817-821.

40. Oishi A, Tobimatsu S, Arakawa K, Tanikawi T, Kira J-I. Ocular dominancy in conjugate eye movements at reading distance. Neurosci Res. 2005;52:263-268. 